\title{
PERENCANAAN ENTERPRISE ARSITEKTUR MENGGUNAKAN ZACHMAN FRAMEWORK PADA PT XY MARKETING DAN PROMOSI
}

\author{
Sukrina Herman'1, Yunita², Ahsani Takwim ${ }^{3}$ \\ 1STMIK LIKMI \\ e-mail: sukrinahermanheral01@gmail.com \\ 2STMIK LIKMI \\ e-mail: yunita.nambela@gmail.com \\ 3STMIK LIKMI \\ e-mail: ahsanitakwim10@gmail.com
}

\begin{abstract}
Abstrak
Dengan semakin meningkatnya perkembangan teknologi, semakin banyak pula ragam aplikasi yang dibangun untuk menunjang kebutuhan suatu perusahaan. PT XY adalah perusahan yang bergerak dalam bidang produksi dan penjualan produk function. Dalam menjalankan proses bisnisnya perusahaan ini sangat mengutamakan (goods) barang dan (service) layanan yang berkualitas, sehingga menuntut fungsi marketing dan promotion untuk mempunyai strategi dan kinerja pemasaran yang sesuai dengan tujuan utama perusahaan. Model enterprise architecture yang akan digunakan yaitu dengan menggunakan enterprise architecture planning (EAP). EAP merupakan suatu metode yang digunakan untuk merancang enterprise architecture dengan memfokuskan pada arsitektur data, aplikasi, dan teknologi untuk mendukung bisnis dan rencana untuk mengimplementasikan arsitektur tersebut. Dalam menggunakan metode EAP nantinya akan menggunakan tahapan planning initation, business modelling, system dan teknologi saat ini, arsitektur data, arsitektur aplikasi, arsitektur teknologi dan rencana implementasi. Dalam perancangan ini menggunakan Zachman Framework. Zachman framework adalah skema yang digunkan untuk klasifikasi pengorganisasian artifak enterprise. Hasil dari penelitian ini berupa blueprint perencanaan EAP.
\end{abstract}

Kata Kunci: EAP, Blueprint, initation, business modelling.

\begin{abstract}
With the increasing development of technology, more and more variety of applications are built to support the needs of a company. PT XY is a company engaged in the production and sale of function products. In running the business process the company is very prioritizing (goods) goods and (service) quality services, thus demanding the function of marketing and promotion to have a marketing strategy and performance in accordance with the main objectives Company. The enterprise architecture Model to be used is to use Enterprise architecture Planning (EAP). EAP is a method used to design enterprise architecture by focusing on data architecture, applications, and technology to support businesses and plans to implement those architectures. In using the EAP method will later use the planning stage initation, business modelling, current system and technology, data architecture, application architecture, technology architecture and implementation plan. In this design use the Zachman Framework. Zachman Framework is a scheme used to classify the organization artifact of the Enterprise. The result of this research was EAP planning blueprint.
\end{abstract}

Keywords: EAP, Blueprint, initation, business modelling. 


\section{Pendahuluan}

Kemajuan teknologi yang terus berkembang memungkinkan untuk setiap perusahaan untuk memiliki keakuratan data dan aplikasi. Oleh karena itu kemajuan teknologi informasi harus terus di upayakan untuk ditingkatkan kualitas dan kuantitasnya. Selain itu, dengan perkembangan teknologi saat ini mampu menciptakan suatu persaingan yang kompetitif untuk penerapan IS / IT di perusahaan. Dengan adanya kolaborasi antara teknologi informasi dan ilmu pengetahuan serta bidang ilmu lainnya dapat membantu dalam perkembangan teknologi pada era sekarang (Adhani et al., 2015). Dengan penggunaan teknologi informasi dalam dunia bisnis akan membantu mempermudah setiap pebisnis untuk menciptakan keunggulan yang kompetitif yang mampu bersaing dalam pasar global (Pada et al., 2015). Degan banyaknya ritel didunia menjadi bukti bahwa banyaknya konsumen yang menggunakan internet dalam kehidupan sehari seperti perdangan via online (E-Commnerce). Menurut Shim et al. (2000) dalam suyanto (2003) proses jual beli pada internet disebut sebagai ecommerce(Maryama, 2018)

Ada 6 efek positif penggunaan ecommerce yaitu peningkatan efisiensi, biaya yang dikeluarkan lebih hemat, dapat membantu mengintrol barang, dapat mempermudah memperbaiki supply chain dan menjaga hubungan baik perusahaan dengan supplier (pemasok)(Yau, 2002)(Maryama, 2018). Dengan adanya ECommerce dapat membantu mempermudah komunikasi antara produsen dan konsumen untuk memperluas target pasar dan mempermudah pemasaran dan promosi barang ataupun jasa, proses pembelian dan penjualan barang yang lebih efektif, pembayaran yang dapat dilakukan secara online, penyebaran informasi yang efektif dan efisien untuk dilakukan(Achjari, 2000)

Perusahaan PT XY belum adanya panduan Architecture reference dan strategi pengembangan IT yang menyebabkan naik dan turunnya profit yang dialami oleh perusahaan. Seperti halnya pada fungsi promotion dimana adanya kendala yang terdapat pada aplikasi, dimana belum terdapat aplikasi yang mengcover beberapa proses bisnis dan belum terintegrasi satu sama lainnya yang berdampak ke komunikasi antara user yang tidak berjalan efektif, pertukaran informasi yang kurang baik dan proses bisnis pun belum berjalan secara baik. Dari hal tersebut cukup banyak ditemukan permasalahan seperti human error atau miss communication antar sesama divisi dan internal divisi itu sendiri karena tidak adanya pendokumentasian yang baik tentang segala hal yang berhubungan dengan promosi yang berdampak pada jalannya proses bisnis yang tidak efektif. sehingga hal ini bisa menjadi kendala yang cukup berpengaruh terhadap keberhasilan dalam mencapai goals dalam suatu perusahaan maupun divisi. Enterprise Architecture merupakan suatu perencanaan, perancangan dan pengelolaan infrastruktur $\mathrm{SI} / \mathrm{TI}$, serta mampu mengintegrasikan $\mathrm{SI} / \mathrm{TI}$ di dalam suatu arsitektur. Menurut The Open Group, dapat disimpulkan Enterprise Architecture adalah blueprint organisasi yang menentukan bisnis, informasi, dan teknologi yang digunakan agar tercapai misi organisasi (Spencer, 2003).

Enterprise Architecture berfungsi sebagai penyedia cetak biru atau kerangka dasar (blueprint) untuk sistem dan selama proses berlangsungnya proyek pengembangan sistem tersebut dan dapat digunakan sebagai jalan untuk meningkatkan efisiensi TI pada saat inovasi bisnis dikembangkan perusahaan (Irfanto \& Andry, 2017). EA dikonsentrasikan pada infrastruktur yang meliputi hardware, software dan network untuk dapat bekerja secara bersama dengan misi, sasaran, dan tujuan organisasi untuk menjalankan proses bisnis organisasi dengan didukung oleh teknologi informasi.

Dalam pengembangan EA terdapat berbagai macam framework yang dapat dimanfaatkan untuk pengembangan EA, diantaranya yaitu menggunakan zachman Framework (Slameto et al., 2012).

\section{Zachman Framework}

Zachman framework merupakan sebuah skema yang digunkan untuk klasifikasi pengorganisasian artifak enterprise (Zachman, 1987). Penerapan Framework Zachman Pada Arsitektur Pengelolaan Data Operasional (Studi Kasus SBU Aircraft Service, PT Dirgantara Indonesia). Seminar Nasional Aplikasi Teknologi Informasi Yogyakarta.) Zachman Framework adalah framework EA yang menyediakan cara untuk memandang dan mendefinisikan enterprise baik formal ataupun terstruktur dengan baik yang 
memiliki beberapa pertanyaan umum yaitu What, Where, When, Why, Who dan How.

a. What (data) lebih menggambarkan kesatuan yang sangat penting dalam bisnis.

b. How (fungsi) menjelaskna input dan output berserta fungsi dan aktifitas.

c. Where (jarinagn) lebih menunjukkan lokasi dan geografis serta hubungan antara aktifitasi dalam organisasi.

d. Who (manusia) lebih kepengukuran kemampuan dan kinerja yang mewakili manusia dalam organisasi. e. When (waktu) mewakili waktu dan meunjukkan kinerja kerja.

f. Why (motivasi) lebih menjelaskan moivasi dari organisasi dan perkerjaannya (Kurniawan \& Kom, n.d.).

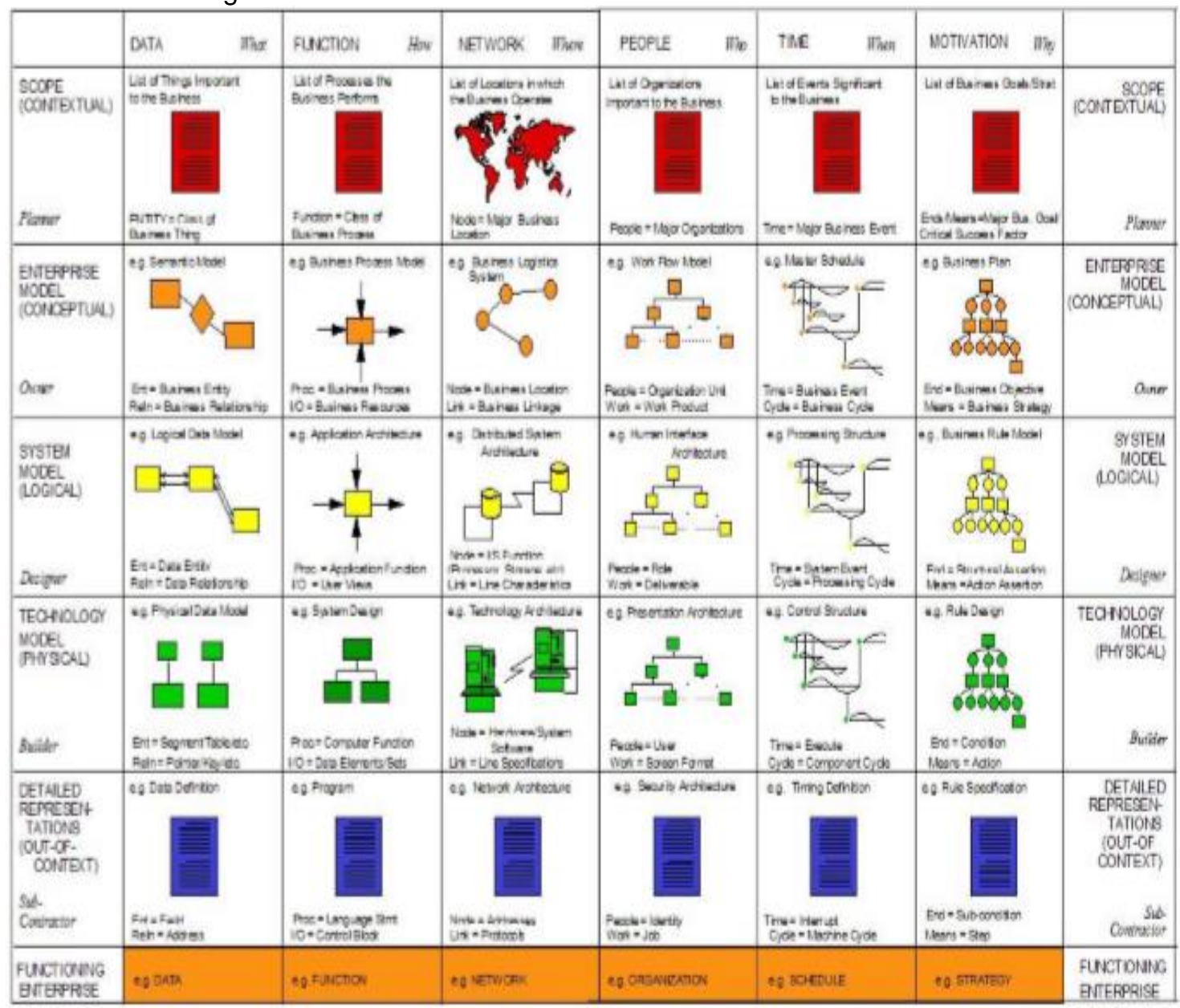

Gambar 1. Zachman Framework

\section{EAP (Enterprise Architetcure Planning)}

EAP merupakan metode yang digunakan untuk membangun sebuah arsitektur informasi dengan pendekatan perencanaan kualitas data yang berorientasi pada kebutuhan bisnis dengan melihat bagaimana implementasi dari arsitektur untuk pencapaian isi system informasi dan organisasi (Irfanto \& Andry, 2017).
Dalam EAP menjelaskan mengenai data, aplikasi dan teknologi yang dibutuhkan untuk mendukung bisnis organisasi.

a. Lapisan 1 (Posisi memulainya)

Tahap ini menghasilkan rencana kerja, kepastian komitmen manajemen.

b. Lapisan 2 (Posisi sekarang)

- Pemodelan bisnis

- System dan teknologi saat ini

c. Lapisan 3 
$\checkmark$ Arsitektur Data: menggambarkan struktur aset data logik dan fisik serta resource manajemen data dari suatu perusahaan.

$\checkmark$ Arsitektur aplikasi: menjelaskan tentang aplikasi yang dibangun, dan hubungan dengan bisnis proses utama perusahaan

$\checkmark$ Arsitektur teknologi menggambarkan kemampuan software dan hardware yang dibutuhkan untuk mendukung pembangunan layanan bisnis, data dan aplikasi.

d. Lapisan 4 (Bagaimana cara mencapainya) yaitu menentukan tahapan penerapan aplikasi, jadwal penerapan dan jalur yang jelas dari posisi saat ini ke posisi mendatang (Irfanto \& Andry, 2017).

Oleh karena itu, dalam paper ini menggunakan metode EA menggunakan pendekatan Zahcman Framework untuk membantu membuat rencana strategis system informasi, sehingga dapat diukur proses dan hasil implementasinya.

\section{Metode Penelitian}

Metodologi penelian yang digunakan untuk membuat rancangan EA dengan metode Zachman Framework yaitu dengan melakukan penelusuran pustaka dan melakukan pengamatan langsung.

Model konseptual merupakan sebuah rancangan yang terstruktur dari kumpulan konsep yang saling terkait untuk melihat relasi dan pengaruh antar konsep. Model konseptual ini memungkinkan kita untuk mengamati dan menghasilkan output yang sesuai dengan tujuan penelitian. Model konseptual berupa struktur organisasi, rencana strategi, proses binsis, visi dan misi dan kondisi eksisting TI pada perusahaan. Dalam metode konseptual ini hal yang harus dilakukan yaitu:

1.Memahami kondisi existing perusahaan dengan melihat proses bisnis

2. Memehami sistem dan teknologi yang digunakan

3. Melakukan perancangan EA dengan melakukan identifikasi dan memehami.

\section{Hasil dan Pembahasan}

Setelah melakukan proses pengumpulan data, selanjutnya memetakan masalah kedalam zachman untuk menghasilkan sebuah rancangan. Setelah masalah didapatkan selanjutnya masalah tersebut disusun menjadi kerangka matriks zachman.

\subsection{Inisiasi Perencanaan (Planning Initiation)}

Tahap awal yang dilakukan untuk melakukan perencanaan EAP dengan metode zachman Framework yaitu memahami ataupun mengetahui visi dari perencanaan SI, ruang lingkup, dan tujuan agar sesuai dengan proses bisnisyang dijalani perusahaan. Ruang lingkup pengerjaan:

1. Perencanaan Arsitektur Data

2. Perencanaan Arsitektur Aplikasi

3. Perencanaan Arsitektur Teknologi

\subsection{Pemodelan Bisnis (Business Modelling)}

Pada tahap ini penulis melakukan Analisa dengan melakukan analisis fungsi bisnis yang mendalam dari masing kumpulan aktivitas dengan menggunakan value chain. Value chain Diagram merupakan metode untuk menganalisis aktivitas-aktivitas pada perusahaan, baik aktivitas pendukung maupun aktivitas utama untuk menghasilkan value bagi customer. Berikut value chain perusahan $\mathrm{PT}$. XY.

\begin{tabular}{|c|c|c|c|c|}
\hline \multicolumn{4}{|c|}{ Firm Infrastructures } & \multirow{4}{*}{ Profit } \\
\hline \multicolumn{4}{|c|}{ Human Resource Development } & \\
\hline \multicolumn{4}{|c|}{ Technology Development } & \\
\hline Produksi & $\begin{array}{c}\text { Distribusi } \\
\quad \text { dan } \\
\text { Warehousing }\end{array}$ & Marketing & Penjualan & \\
\hline
\end{tabular}

Gambar 2. Value Chain

Pada table 1 dan 2 menggambarkan proses fungsi dengan organisasi pada fungsi promosi dan marketing. Pada proses fungsi promotion terdapat beberapa fungsi yaitu pengelolaan pendataan reseller, pengelolaan report penjualan dan pengelolaan pengiriman barang. 
Tabel 1. Proses Fungsi Promotion

\begin{tabular}{|l|c|c|c|}
\hline $\begin{array}{l}\text { Fungsi/ } \\
\text { Organis } \\
\text { asi }\end{array}$ & $\begin{array}{l}\text { Pengelol } \\
\text { aan } \\
\text { pendataa } \\
\text { n reseller }\end{array}$ & $\begin{array}{l}\text { Pengelol } \\
\text { aan } \\
\text { report } \\
\text { penjualan }\end{array}$ & $\begin{array}{l}\text { Pengelol } \\
\text { aan } \\
\text { pengirima } \\
\text { n barang }\end{array}$ \\
\hline Direktur & $\mathrm{v}$ & & \\
\hline $\begin{array}{l}\text { Finance } \\
\& \\
\text { Accounti } \\
\mathrm{ng}\end{array}$ & & $\mathrm{v}$ & \\
\hline $\begin{array}{l}\text { Staff } \\
\text { Distribus } \\
\mathrm{i}\end{array}$ & & & $\mathrm{v}$ \\
\hline $\begin{array}{l}\text { Staff } \\
\text { Divisi } \\
\text { Marketin } \\
\mathrm{g}\end{array}$ & $\mathrm{v}$ & $\mathrm{v}$ & $\mathrm{v}$ \\
\hline $\begin{array}{l}\text { Divisi } \\
\text { Marketin } \\
\mathrm{g}\end{array}$ & $\mathrm{v}$ & $\mathrm{v}$ & $\mathrm{v}$ \\
\hline Cargo & & & \\
\hline
\end{tabular}

Pada tabel dibawah ini menggambarkan proses fungsi marketing yang hanya memiliki satu fungsi yaitu pengelolaan pengajuan reseller.

Tabel 2. Proses Fungsi Marketing

\begin{tabular}{|l|c|}
\hline $\begin{array}{l}\text { Fungsi/ } \\
\text { Organisasi }\end{array}$ & $\begin{array}{l}\text { Pengelolaan } \\
\text { pengajuan reseller }\end{array}$ \\
\hline Direktur & $\mathrm{v}$ \\
\hline Finance \& Accounting & \\
\hline Staff Distribusi & \\
\hline Staff Divisi Marketing & $\mathrm{v}$ \\
\hline Divisi Marketing & $\mathrm{v}$ \\
\hline Cargo & \\
\hline
\end{tabular}

3.3. Arsitektur Sistem dan Teknologi Saat Ini

Berikut identifikasi platform teknologi yang terdapat dalam suatu enterprise. Pada tabel 3 menggambarkan matriks aplikasi fungsi promosi yang menggambarkan fungsi dengan aplikasi. Pada fungsi promosi memiliki satu aplikasi yaitu www.houseofsmith.co.id.
Tabel 3. Matriks Aplikasi Fungsi Promosi

\begin{tabular}{|c|c|c|c|c|c|c|c|c|c|c|}
\hline $\begin{array}{l}\text { Fungs } \\
\text { i/ } \\
\text { Aplika } \\
\text { si }\end{array}$ & 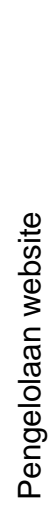 & 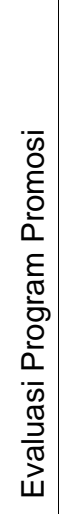 & 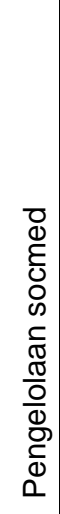 & 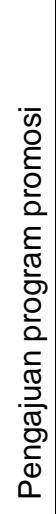 & 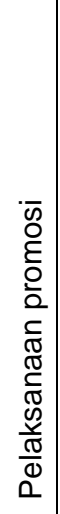 & 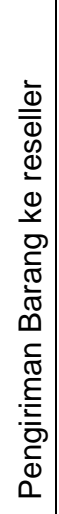 & 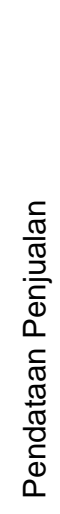 & 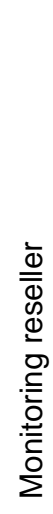 & 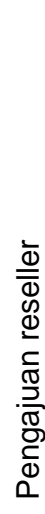 & 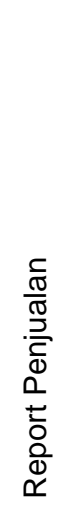 \\
\hline $\begin{array}{l}\text { www. } \\
\text { house } \\
\text { ofsmit } \\
\text { h.co.i } \\
\text { d }\end{array}$ & $\mathrm{v}$ & $x$ & $\mathrm{v}$ & $\mathrm{v}$ & $x$ & $x$ & $x$ & $x$ & $x$ & $x$ \\
\hline
\end{tabular}

Pada table 4 menggambarkan aplikasi fungsi marketing. Dimana pada fungsi marketing ini memiliki dua aplikasi yaitu www.houseofsmith.co.id dan revote.

Tabel 4. Aplikasi Fungsi Marketing

\begin{tabular}{|c|c|c|c|c|c|c|c|c|c|c|}
\hline $\begin{array}{l}\text { Fungsi / } \\
\text { Aplikasi }\end{array}$ & $\begin{array}{l}\frac{1}{10} \\
\frac{0}{0} \\
3 \\
\frac{1}{0} \\
\frac{\pi}{0} \\
\frac{0}{0} \\
\frac{0}{0} \\
0 \\
0\end{array}$ & 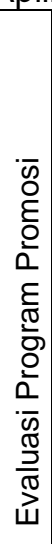 & 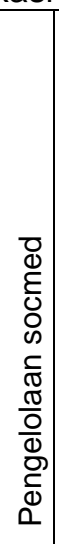 & 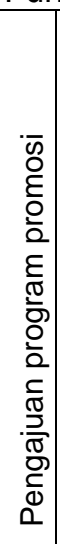 & 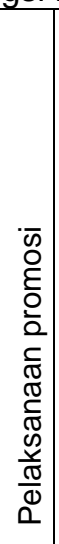 & 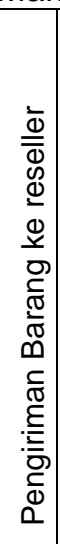 & 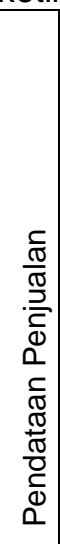 & 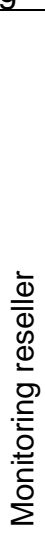 & 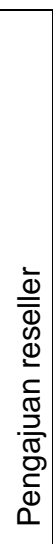 & 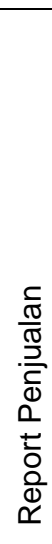 \\
\hline $\begin{array}{l}\text { www.ho } \\
\text { useofs } \\
\text { mith.co. } \\
\text { id }\end{array}$ & $x$ & $x$ & $x$ & $x$ & $x$ & $x$ & $x$ & $x$ & v & $x$ \\
\hline Revota & $x$ & $x$ & $x$ & $x$ & $x$ & $\mathrm{v}$ & $\mathrm{v}$ & $x$ & $x$ & v \\
\hline
\end{tabular}

\subsection{Arsitektur Data}

Berikut adalah tabel 5 dan tabel 6 untuk arsitektur data yang menggambarkan fungsi entitas data pada fungsi promosi dan fungsi marketing.

Pada tabel 5 menggambarkan entitas data promosi. Dimana pada tabel ini 
menggambarkan hubungan setiap entity dengan proses bisnis.

Tabel 5. Entitas Data Promosi

\begin{tabular}{|c|c|}
\hline Entity & Proses Bisnis \\
\hline \multirow{4}{*}{ Produk } & Pengelolaan website \\
\cline { 2 - 2 } & Evaluasi program promosi \\
\cline { 2 - 2 } & Pengelolaan socmed \\
\cline { 2 - 2 } & $\begin{array}{c}\text { Pengajuan program } \\
\text { promosi }\end{array}$ \\
\cline { 2 - 2 } Customer & Pelaksanaan promosi \\
\hline \multirow{4}{*}{ Penjualan } & Pelaksanaan promosi \\
\cline { 2 - 2 } & Pengelolaan website \\
\cline { 2 - 2 } & Evaluasi program promosi \\
\hline Pegawai & Pelaksanaan promosi \\
\hline \multirow{4}{*}{ User } & Evaluasi program promosi \\
\cline { 2 - 2 } & Pengelolaan socmed \\
\cline { 2 - 2 } & Pengelolaan website \\
\cline { 2 - 2 } & Pelaksanaan promosi \\
\hline \multirow{4}{*}{ Feedback } & Pengelolaan website \\
\cline { 2 - 2 } & Evaluasi program promosi \\
\hline
\end{tabular}

Pada tabel 6 ini menggambarkan entitas data marketing. Pada tabel ini juga menggambarkan hubungan setiap entity dengan proses bisnis pada fungsi data marketing khususnya.

Tabel 6. Entitas Data Marketing

\begin{tabular}{|c|c|}
\hline Entity & Proses Bisnis \\
\hline Produk & $\begin{array}{c}\text { Pengiriman barang ke } \\
\text { reseller }\end{array}$ \\
\hline Penjualan & Report penjualan \\
\hline Pegawai & - \\
\hline Delivery & $\begin{array}{c}\text { Pengiriman barang ke } \\
\text { reseller }\end{array}$ \\
\hline \multirow{3}{*}{ User } & Pendataan reseller \\
\hline & $\begin{array}{c}\text { Pengiriman barang ke } \\
\text { reseller }\end{array}$ \\
\hline & Report penjualan \\
\hline $\begin{array}{l}\text { Channel } \\
\text { (Cargo) }\end{array}$ & $\begin{array}{c}\text { Pengiriman barang ke } \\
\text { reseller }\end{array}$ \\
\hline \multirow{3}{*}{$\begin{array}{l}\text { Data } \\
\text { Reseller }\end{array}$} & Pengajuan reseller \\
\hline & Pendataan reseller \\
\hline & Monitoring reseller \\
\hline
\end{tabular}

\begin{tabular}{|c|c|}
\hline Entity & Proses Bisnis \\
\hline Received & $\begin{array}{c}\text { Pengiriman barang ke } \\
\text { reseller }\end{array}$ \\
\hline
\end{tabular}

\subsection{Arsitektur Aplikasi}

Berikut adalah tabel 7, tabel 8 dan tabel 9 untuk arsitektur aplikasi yang menggambarkan fungsi pada proses marketing, proses promosi dan aplikasi revote.

Pada tabel 7 menjelaskan aplikasi proses marketing, dimana pada fungsi marketing ini ada website yang digunakan yaitu www.houseofsmith.co.id. Dalam website menggambarkan hubungan application component dengan business process.

Tabel 7. Aplikasi Proses Marketing

\begin{tabular}{|l|l|}
\hline \multicolumn{2}{|c|}{ www.houseofsmith.co.id } \\
\hline \multicolumn{2}{|c|}{ Marketing } \\
\hline $\begin{array}{l}\text { Application Component } \\
\text { (x) / Business Process (y) }\end{array}$ & $\begin{array}{l}\text { Pengelolaan } \\
\text { pengajuan } \\
\text { reseller }\end{array}$ \\
\hline Pengajuan reseller & $\mathrm{v}$ \\
\hline
\end{tabular}

Pada tabel 8 menjelaskan aplikasi proses promosi, dimana pada fungsi promosi juga menggunakan website yang digunakan yaitu www.houseofsmith.co.id. Dalam website menggambarkan hubungan application component dengan business process seperti tabel dibawah ini.

Tabel 8. Aplikasi Proses Promotion

\begin{tabular}{|l|l|l|l|}
\hline \multicolumn{5}{|c|}{ www.houseofsmith.co.id } \\
\hline \multicolumn{4}{|c|}{ Promotion } \\
\hline Applicati & Pengelol & Pengelol & Pengelol \\
on & aan & aan & aan \\
Compon & pengajua & media & Website \\
ent (x)/ & $\mathrm{n}$ & sosial & \\
Business & program & & \\
Process & promosi & & \\
(y) & & & \\
\hline Pengajua & $\mathrm{V}$ & & \\
$\mathrm{n}$ & & & \\
program & & & \\
promosi & & & \\
\hline Pengelol & & $\mathrm{V}$ & \\
aan & & & \\
Media & & & \\
Sosial & & & $\mathrm{V}$ \\
\hline Pengelol & & & \\
aan & & & \\
website & & & \\
\hline
\end{tabular}

Pada tabel 9 menggambarkan aplikasi Revota. Dimana pada aplikasi ini 
terdapat menu pendaftaran reseller, report penjualan dan pengiriman barang.

Tabel 9. Aplikasi Revota

\begin{tabular}{|c|c|c|c|}
\hline \multicolumn{4}{|c|}{ Revota } \\
\hline $\begin{array}{l}\text { Applicati } \\
\text { on } \\
\text { Compon } \\
\text { ent }(\mathrm{x}) / \\
\text { Business } \\
\text { Process } \\
\text { (y) }\end{array}$ & $\begin{array}{l}\text { Pengelol } \\
\text { aan } \\
\text { pendataa } \\
\mathrm{n} \text { reseller }\end{array}$ & $\begin{array}{l}\text { Pengelol } \\
\text { aan } \\
\text { report } \\
\text { penjuala } \\
\mathrm{n}\end{array}$ & $\begin{array}{l}\text { Pengelol } \\
\text { aan } \\
\text { pengirim } \\
\text { an } \\
\text { barang }\end{array}$ \\
\hline $\begin{array}{l}\text { Pendafta } \\
\text { ran } \\
\text { reseller }\end{array}$ & v & & \\
\hline $\begin{array}{l}\text { Report } \\
\text { penjuala } \\
\mathrm{n}\end{array}$ & & $\mathrm{v}$ & \\
\hline $\begin{array}{l}\text { Pengirim } \\
\text { an } \\
\text { barang }\end{array}$ & & & v \\
\hline
\end{tabular}

\section{Kesimpulan}

Berdasarkan hasil penelitian dapat disimpulkan bahwa:

1. Dalam penelitian ini menghasilkan Analisa dan perancangan menggunakan metode EAP dengan pendekatan zachman framework yang dilakukan pada perusahaan PT.XYZ dengan studi kasus fungsi Promosi dan Marketing

2. Dengan adanya rancangan dan Analisa ini dapat melihat aplikasi dan data yang digunakan oleh perusahaan.

\section{Saran}

Berdasarkan hasil penelitian yang dilakukan diharapkan perlunya melakukan pengembangan menggunakan metode framework lain seperti TOGAF, FEAF dan Garnert untuk memperoleh hasil yang lebih baik lagi.

\section{Referensi}

Achjari, D. (2000). Potensi Manfaat Dan Problem Di E-Commerce. Jurnal Ekonomi Dan Bisnis Indonesia, 15(3), 388-395. http://www.amazon.com

Adhani, M., Abdillah, L. A., Widayati, Q., Studi, P., Informasi, S., Komputer, F. I., Darma, U. B., Studi, P., Informasi, S., Komputer, F. I., \& Darma, U. B. (2015). Analisa dan perancangan sistem informasi penerimaan siswa baru dan pembayaran spp menggunakan zachman framework. 641-647.

Irfanto, R., \& Andry, J. F. (2017). PERANCANGAN ENTERPRISE ARCHITECTURE MENGGUNAKAN
ZACHMAN FRAMEWORK ( STUDI KASUS : PT . VIVAMAS ADIPRATAMA ). November, 1-2.

Kurniawan, B., \& Kom, M. (n.d.). ENTERPRISE ARCHITECTURE PLANNING SISTEM INFORMASI. 9(1), 21-32.

Maryama, S. (2018). Penerapan ECommerce Dalam Meningkatkan Daya Saing Usaha. Liquidity, 2(1), 73-79. https://doi.org/10.32546/lq.v2i1.132

Pada, L., Jasa, P., \& Swasta, L. (2015). No Title. 3(1).

Slameto, A. A., Utami, E., Pangera, A. A., Magister, M., Informatika, T., Sarjana, P. P., Magister, D., Informatika, T., Sarjana, P. P., Pelaporan, S., \& Informasi, T. (2012). ANALISIS DAN DESAIN ARSITEKTUR ENTERPRISE. 37-52.

Spencer, J. (2003). TOGAF - The Open Group Architecture Framework. October.

Yau, O.B. ,2002, An Emprical Investigation of the Impact of Business to Busines Electronic Commerce Adoption on the Business Operation of Hong Kong Manufacturers, First Monday, Vol.7 No.9.

Zachman, J. A. (1987). A framework for information systems architecture. 26(3). 